\title{
LA DERIVA DOCUMENTAL DE LA LITERATURA DE PASOLINI: EMPLEO Y ACTUALIZACIONES DE LA LITERATURA CLÁSICA ESPAÑOLA DEL SIGLO XVII (LA VIDA ES SUEÑO) PARA DOCUMENTAR LA REALIDAD ITALIANA DEL SIGLO XX
}

\section{THE DOCUMENTARY DRIFT OF PASOLINI'S LITERATURE: USE AND REVIEW OF THE SEVENTEENTH-CENTURY SPANISH CLASSIC LITERATURE (LIFE IS A DREAM), TO DOCUMENT THE ITALIAN REALITY OF THE TWENTIETH CENTURY}

\author{
Loreta DE STASIO \\ Universidad del País Vasco \\ loreta.destasio@ehu.eus
}

Resumen: El teatro de Pasolini es un teatro documento de inspiración brechtiana que ha sido malinterpretado como teatro regresivo, por ser conceptualista, elitista, y contradictorio, porque dirigido a la burguesía, que Pasolini, sin embargo, detestaba y quería derrumbar. La relación aberrante entre Poder e individuo representada en manera traumática y escandalosa en Saló encuentra su gestación en la escritura teatral de sus tragedias. Calderón de Pasolini resulta interesante en esta dinámica porque es una sugestiva mezcla de referencias e inspiraciones y un importante modelo de intertextualidad, entre ensayo, piéce teatral, happening, ficción literaria y documental histórico.

Palabras clave: Pasolini. Teatro. Documentalidad. Literatura. Calderón. Tragedia. Metateatralidad.

Abstract: Pasolini's theatre is a documentary theatre inspired by Brecht that has been misinterpreted as regressive theatre, for being conceptualist, elitist, and contradictory, as it was addressing the bourgeoisie which Pasolini, however, hated and wanted to collapse. The aberrant relationship between the Power and the individual represented in a traumatic and shocking way in Saló finds its gestation in the playwriting of his tragedies. Pasolini's Calderón is interesting in this dynamic because it is an evocative mixture of references and inspirations as well as an important model of intertextuality test among piéce theatre, happening, literary fiction and historical documentary.

KeyWords: Pasolini.Theatre. Documentary.Literature.Calderón.Tragedy.Metatheatricality. 


\section{PÓRTICO}

La intención documentalista de la producción artística de Pier Paolo Pasolini parece evidente por la elección de la realidad como materia literaria, especialmente por las relaciones humanas y su involución o alteración en la contemporaneidad, tal y como se registra en muchas de sus obras, y, en particular, en las de los últimos años. Su última novela, publicada póstuma, Petróleo, es un testimonio irrefutable de esta orientación del autor, aunque podríamos decir lo mismo de sus primeras novelas y sus primeras películas.

Carla Benedetti recuerda, sin embargo, que, a finales de octubre de 1995, en el curso de las celebraciones del 20 aniversario de la muerte de P.P. Pasolini, el célebre escritor Eduardo Sanguineti, en la revista MicroMega, en una sección dedicada al escritor asesinado, el 2 de noviembre de 1975, escribía que la última producción de Pasolini, la literaria y la cinematográfica, no era más que el "documento" de una desesperación muy privada, cuyo"fondo sadomaso" se expresaba "a través de una patología muy manifiesta"; así que no queda que olvidarla, incluyendo también Petroleo, "cuyos resultados catastróficos se pueden considerar el equivalente de Salò"1.

A una distancia de 20 años de esta declaración sobre Pasolini -como opinión difundida y compartida durante mucho tiempo por algunos intelectuales italianos-, lo que queremos corroborar es la insustancialidad de esta visión. Se ha escrito mucho sobre su producción artística — que incluye poesía, cuentos, novela, cine, ensayos, pintura-, pero poco se ha comentado sobre la actualidad de su teatro que, aparentemente, miraba hacía el pasado, incluso hasta la tragedia griega. Con este estudio intentamos demonstrar que la refinada, compleja re-visitación y actualización del teatro antiguo en Pasolini, como teatro épico, así como el componente surrealista de algunas de sus pièces, producen un teatro profundo, original y vigente todavía hoy.

\section{LITERATURA VS. DOCUMENTO}

Desde nuestro punto de vista, el teatro de Pasolini es un teatro documento, pero de "mirada literaria", con dimensión estética en sí. A través de un texto literario, un documentalista puede llegar a un conocimiento histórico más "significante"2 —es decir, puede "ver más", reclamar, a través de la perspectiva literaria, "el derecho a una segunda

1 E. Sanguineti (1995), "Radicalismo e patologia”. Veánse el interesante texto de Carla Benedetti (1998), Pasolini contro Calvino: per una letteratura impura.

2 Renato Barilli (1970: 8), “La metamorfosi della narrativa”, en la introdución a Robert Scholes y Robert Kellog, La natura della narrativa. 


\section{DOCUMENTAR LA REALIDAD ITALIANA DEL SIGLOXX}

mirada"3 - es posible incluso prescindir de la "calidad" del texto, sin cuestionar el valor artístico de la obra-fuente de información.

Por su parte, la literatura, con su ficción, incluso la irreal, o surreal, prevé y construye documentos históricos reales. La literatura está capacitada para contarnos la verdad en una construcción compleja que, a través de la interacción de las estructuras del texto y de la ficción con respecto a la realidad, pone de relieve las diferentes perspectivas de una situación. Si la verdad de la historia no puede prescindir del tiempo y del lugar de la realidad objeto de estudio - ya que su verdad no puede no estar "históricamente determinada" - la cooperación de estas dos disciplinas esclarece aún más la realidad. La verdad de la historia y la literatura no son contradictorias: es más, las dos juntas son capaces de iluminar mejor nuestro conocimiento 4 .

Lo que está en juego es la relación verdad / ficción que es el macro-tema que justifica el uso de Pasolini (2001b) del drama de Calderón de la Barca. Esta relación está en la base de la revolución pirandelliana del siglo XX, y da lugar a la modernidad, pese a que la filosofía dialéctica que aclara las cuestiones de la vida social ya había inspirado a Shakespeare en el teatro inglés, en el siglo XVI.

Por otro lado, al igual que el modo del documental es una forma experimentada por los más prestigiosos directores del neorrealismo italiano como ejercicio para madurar una poética más original, también el Calderón se puede considerar un experimento metaartístico de Pasolini en este sentido: esta tragedia es un híbrido de intertextualidad cultural (la referencia es clara y metonímica a La vida es sueño, la obra más famosa del autor barroco español Calderón de la Barca) e intersemióticidad: pintura (Las meninas de Velázquez), historia, fotografía y cine: Pasolini se basa en la memoria cultural común sobre la corte española del siglo XVII, ilustrada a través de su inserción —como escena dramática - en un famoso cuadro, Las Meninas, de Velázquez; también hace referencia a la guerra civil española y a las aberraciones franquistas, a un campo de concentración nazi, a la realidad de los suburbios de las grandes ciudades españolas, a la aristocracia española del siglo XVII, y a la alta burguesía madrileña de los años 40 y del final de los 60. Con Calderón más que con otras tragedias, ha teatralizado un discurso coherente y apasionadamente apoyado de forma continua en ensayos periodísticos, filosóficos y sociológicos, denunciando la corrupción humana, la discriminación, la explotación y la

3 Jean Starobinskj (1975: 10), L'occhio vivente. Studi su Corneille, Racine, Stendhal, Freud. El "ver más", al que se hace referencia aquí contempla la posibilidad de una extensión del sentido del conocimiento histórico, y no el aspecto icónico-lingüístico. Veánse Giovanni Pozzi (1981), La parola dipinta y, sobre todo, Paolo Favilli, ed. (2013: 28), Il letterato e lo storico: la letteratura creativa come storia.

4 Alberto Asor Rosa (2013: 216), sin embargo, pone el problema del significado que pueden compartir la historia y la literatura, porque si bien es cierto que tienen un campo común de conocimientos, ese se funda sobre diferentes estructuras epistemológicas, con lo cual propone de intervenir sobre los mecanismos de cambio de "paradigma". 
lucha de clase. Y el autor lo declara en Affabulazione: "El hombre sólo se dio cuenta de la realidad cuando la representaba. Y nada mejor que el teatro nunca ha sido capaz de representarla" (Pasolini: 2001b: 514, 520)

\section{EL DOCUMENTAL, PRERROGATIVA (EN VENTAJA) DEL RECEPTOR}

La función primitiva del documental es informar sobre una realidad específica, quizá de una manera más o menos objetiva, haciendo que, a través de las imágenes, la realidad se presente por sí sola. Obviamente, la objetividad es imposible porque siempre habrá el filtro, el punto de vista del autor. Se puede presentar la realidad de muchas maneras, y todas las formas justificarín la función de testimonio de lo real. Sin embargo, el peso del documental, con respeto a una obra de ficción, de narración ficcional, está claramente desequilibrado hacía su receptor, porque la intención del documental es que el espectador con las imágenes o la representación, no sólo sea informado, sino convencido y alarmado por lo que ve. Pasolini estaba muy preocupado en efecto, en el proceso de comunicación-transmisión de datos, por su destinatario empírico, y lo demuestra el gran aparato metatextual que precede, sigue, y a veces incluso interrumpe su producción de ensayos. Véanse, por ejemplo los Escritos corsarios, etc. ${ }^{5}$.

La composición de las tragedias de Pasolini está inspirada, como dice el autor, por la lectura apasionada de los diálogos platónicos durante una larga convalecenciaocurrida en 1966. Destacamos la intención de escritura y consiguiente interpretación de estas obras, por la declaración de Pasolini del'73 sobre el carácter político de Calderón:“Ambirei [...] che la chiave della lettura fosse quella di una politica platonica, quella del Convito o del Fedro"6.

De hecho, el nivel político de estos diálogos no está en el tema, sino en el mecanismo dialógico en sí mismo, ya que quiere invitar a una reflexión pública y al juicio. Es la dimensión convivial (como espacio de confrontación entre personas iguales), el carácter de la dimensión teatral lo que atrae a Pasolini. Pero en lugar de pensar en involucrar

5 En esta tragedia Pasolini tiene muy claro el espectador a quien se dirige. El autor, de hecho, es plenamente consciente de que el destinatario "tiene objetivamente su peso en la obra de arte" (Pasolini, 2001a), "Incontro con Pasolini", en Per il cinema (p. 2973) y la necesidad de apelarse directamente a él es evidente a partir del análisis de muchos de los umbrales de las principales obras de Pasolini. Limitando el análisis a su producción ensayística, la necesidad urgente de Pasolini de apelarse al lector es una clara estrategia autorial, como demuestra la "Nota" al final de Pasión e ideología (1960), una colección de ensayos del autor de la década 1948-1958 (Pasolini, 2009). Veáse en Gian Maria Annovi (2011: 22-23), In the Theater of my Mind: Authorship, Personae, and the Making of Pier Paolo Pasolini's Work.

6 v“Yo aspiraría [...] a que la clave para la lectura fuera la de una política platónica, la del Convito o del Fedro" (Pasolini, Teatro, 2001a: 1932). 


\section{LA DERIVA DOCUMENTAL DE LA LITERATURA DE PASOLINI: EMPLEO Y ACTUALIZACIONES DE LA LITERATURA CLÁSICA ESPAÑOLA DEL SIGLO XVII (LA VIDA ES SUEÑO) PARA DOCUMENTAR LA REALIDAD ITALIANA DEL SIGLOXX}

y abrumar al espectador, provocando que el teatro intervenga en la realidad, según estrategias brechtianas que ya considera superadas, Pasolini "introduce", o mejor dicho, "risucchia" al espectador / lector en la escena, dentro de la tragedia, a través de apelaciones y recursos quizá metalépticos, de enunciación enunciada, con una densa red de referencias cruzadas, así como ocurre en Las meninas $^{7}$ de Velázquez.

Pasolini era consciente de las dificultades, las incoherencias y las contradicciones aparentes de su teatro. Roland Barthes (1991) afirmaba que "la realidad no es representable, sino sólo demostrable ${ }^{8}$ [...] El asunto es que no hay absolutamente ningún paralelismo entre la realidad y el lenguaje", y el teatro de Pasolini parece estar basado en estas premisas, porque lo que quiere enseñar el autor es la "oscuridad, el hermetismo" del universo burgués.

Calderón es también la tragedia en la que los cuerpos que han habitado el espacio absoluto y rico de la corte española, en la más clásica de las pinturas, acaban en la fotografía de un campo de concentración, uno de los documentos más miserables de nuestro tiempo. Esos mismos cuerpos del campo de concentración serán entonces los signos de la perversión del poder que Pasolini quiere desnudar en Saló, escandalizando a los moralistas respetables, y sacudiendo la conciencia de la alta burguesía y de los intelectuales.

La estrategia de Pasolini implica, atrae a los espectadores por impulso voyeurista, pero, narcisísticamente, también se cuestiona a sí mismo como autor, como metaforizados todos por la referencia y la presencia del célebre cuadro de Velázquez, Las Meninas. En esta pintura se incluye el sujeto, el autor de la obra y hace que el retrato, y del mismo modo, Pasolini, de manera ambigua y contradictoria, se incluye en la denuncia que desea ejercer con sus obras 9 .

7 La elección de la tragedia se debe al lenguaje de la conciencia de la diversidad del intelectual y es la forma heroico-victimista contra el poder burgués. Cf. S. Casi (2003: 179), I teatri di Pasolini.

8 La literatura "se afana por representar algo. ¿Qué? Yo diría brutalmente: lo real. Lo real no es representable, y es debido a que los hombres quieren sin cesar representarlo mediante palabras que existe una historia de la literatura. Que lo real no sea representable - sino solamente demostrable - puede ser dicho de diversas maneras: ya sea que con Lacan se lo defina como lo imposible, lo que no puede alcanzarse y escapa al discurso, o bien que, en términos topológicos, se verifique que no se puede hacer coincidir un orden pluridimensional (lo real) con un orden unidimensional (el lenguaje). Ahora bien: es precisamente a esta imposibilidad topológica a la que la literatura no quiere, nunca quiere someterse. Los hombres no se resignan a esta falta de paralelismo entre lo real y el lenguaje, y es este rechazo, posiblemente tan viejo como el lenguaje mismo, el que produce, en una agitación incesante, la literatura", Barthes (1991:127-128), en Lección inaugural de la cátedra de semiología lingüística del Còllege de France.

9 El mismo proceso ocurre, por ejemplo, en Uccellaccie uccellini (Pajaritos y pajarracos, 1966), cuando, durante un viaje surrealista a los lugares imaginarios de una ciudad radiografiada, los protagonistas se encuentran con un cuervo que padre e hijo se comen por hambre y por liberarse de la voz estridente de la ideología que el pájaro representa. En ese cuervo, también hay Pasolini como ideólogo y autor. 
Lo que nos interesa demostrar es que el teatro documental de Pasolini es sí documento, pero no una enfermedad - a menos que no se desee definir patología privada los intereses, las inquietudes sociales, el malestar social y el sentido ético de un escritor, poeta, e intelectual - sino más bien es la evidencia de un cierto período histórico del que se denuncia la aberración. Y lo hace con técnicas y recursos, típicos de lo que se conoce como teatro documental, una forma de teatro también llamado teatro político por Piscator. En otras palabras, el arte teatral como articulación refinada y sincrética de la literatura, no sólo no es incompatible con la función del documento histórico, sino que es necesaria para afrontarlo, para reaccionar y comprender el fenómeno del que el documento es una expresión, y a veces incluso se anticipa a las consecuencias; y, sobre todo, a través de la estimulación del sentido crítico, puede ofrecer posibles respuestas a los problemas que esta tragedia documental quiere demostrar.

Para insertar el Calderón de Pasolini en esta corriente, sería oportuno mencionar cómo y por qué nació el teatro documental, y para ello, es importante recordar los conceptos básicos de este género teatral que remontan a Piscator y Bertolt Brecht, y que debe mucho a las teorías estéticas elaboradas por Peter Weiss.

\section{LA ESTÉTICA DOCUMENTAL}

Brecht, al igual que Piscator, estaba interesado en crear un tipo de teatro capaz de transformar las situaciones socio-políticas de su contexto y confiaba en el marxismo como herramienta para gestionar dichas transformaciones. Su teoría teatral, denominada teatro épico, además de representar la materialización escénica de una labor de tipo marxista es una influencia de enorme valor para la configuración del teatro documento. De hecho, es difícil entender el teatro documental sin conocer algunos elementos brechtianos que están presentes en la estética documental.

Tanto el teatro épico como el documental tienen un alto componente de crítica política. Ambos movimientos teatrales retoman datos y documentos y conducen el argumento a través de hechos históricos y reales para generar cuestiones sobre el comportamiento de la realidad y la literatura.

Brecht al intentar materializar escénicamente la propuesta marxista acude a la tradición de la literatura dialéctica, de modo, que con la representación de sus teorías mediante opuestos, se posibilitase la forma dramática. Pero esta premisa por sí sola no resulta significativa, y para poder llevarla a cabo desarrolló toda una serie de teorías, que en conjunto configurarán el denominado teatro épico (Herrer, 2008: 32). Otro gran aporte que retoma el teatro documental del teatro épico es la incorporación a la escena de la figura narrativa. En el caso del Calderón pasoliniano, el speaker, el locutor, cumple evidentemente esta función, añadidas a otras, como veremos más adelante. 


\section{DOCUMENTAR LA REALIDAD ITALIANA DEL SIGLOXX}

Las múltiples posibilidades que proponen tanto Piscator con su teatro político, como Brecht a través del teatro épico y Peter Weiss mediante sus propuestas éticas y estéticas del teatro documento, continúan siendo herramientas de gran utilización en el teatro actual y explican el estilo del teatro de Pasolini. Estas herramientas, lejos de ocuparse solamente en entretener, divertir, agradar, amenizar, animar, recrear, alegrar y deleitar a un público adormecido y aturdido, se interesan por generar un juicio crítico y una toma de conciencia, que compromete a los espectadores a convertirse en actores generadores de grandes cambios.

\section{EL CALDERÓN}

El título de la pièce es una referencia explícita al gran dramaturgo español Calderón de la Barca, cuya obra maestra, La vida es sueño (1635), es un modelo de composición estimulante para la tragedia de Pasolini. La obra de Calderón de la Barca, como lo demuestra una carta de los años ‘40 dirigida a su amigo Franco Farolfi, es considerada por Pasolini un ejemplo de "sorprendente modernidad". Sólo muchos años después La vida es sueño para Pasolini se convertirá en un medio para afrontar el presente, el de $1967^{10}$.

Titulando un drama con el nombre del autor de la famosa obra del siglo XVII., Pasolini quiere ciertamente referirse metonímicamente al concepto barroco de la dialéctica entre la realidad y el sueño, aunque el homenaje a Calderón y su uso se debe principalmente a la necesidad de estructurar su obra en planos metateatrales para tematizar las estrategias de representación y el sentido de su idea de teatro: las ficciones del escenario funcionales incluso a las no-ficciones y a las ficciones de la vida, los papeles del autor y del espectador / lector y la relación individuo-sociedad. ${ }^{11}$

Muchos de los personajes derivan del mismo drama de Calderón de la Barca, o por lo menos mantienen los nombres: Basilio, que es originalmente un rey polaco, en Pasolini se convierte en un padre y esposo; Segismundo que en drama español es el hijo de Basilio; también está Rosaura, quien es la protagonista femenina y Stella, una princesa, sobrina del rey. A estos personajes y a otros añadidos, son asignados por Pasolini, papeles cambiantes; son personajes utilizados como marionetas, como máscaras de la Comedia del Arte, utilizables en diferentes situaciones: una familia moderna de la rica burguesía española; un grupo de habitantes de tugurios en las afueras de Barcelona; una fantástica familia real de España, cuya escena se encuentra en el famoso cuadro de Las Meninas de Velázquez, contemporáneo de Calderón, y que es la otra fuente de inspiración básica

10 "In questa nottata del 1967" (Pier Paolo Pasolini, Calderón, 2001a: 661).

11 Como en La vida es sueño de Calderón de la Barca se conservan en el Calderón de Pasolini los nombres de Basilio, Segismondo y Rosaura, aunque en el poeta-dramaturgo italiano la atención se desplaza sobre ella como heroína de su tragedia. 
para esta pièce de Pasolini, con la que preserva las similitudes estructurales originales; y también, un hospital mental, las protesta estudiantil de finales de los 60 , y un campo de concentración nazi.

La obra de Pasolini, además de desdoblar a los personajes, los híbrida: el príncipe Segismundo en cadenas, aquí se convierte en otro conocido Segismundo, Sigmund Freud: cuando él aparece Doña Astrea, que está hablando de Freud dice: "Lupus in fabula"; pero es un Freud sólo en parte (medio hebreo, se proclama el personaje) que se revela ex amante de Doña Lupe y padre biológico de Rosaura concebida por violación; en un contexto posterior Segismundo se convierte en abusador de Rosaura y padre de Pablo de quien la misma Rosaura se enamora y está a punto de tener una relación incestuosa con él. Segismundo, en el último contexto es el suegro respetable y reaccionario/conservador de Basilio. Basilio es en cambio, antes padre de Rosaura, luego está en la cabaña de la prostituta Rosaura como figura indistinta y sombría, y finalmente es el marido burgués.

Siguiendo la tradición de Pirandello, Calderón se compone de varios niveles de la realidad representada. Sin embargo, la obra de Pasolini va más allá, explorando no sólo la realidad dentro de la realidad, sino también el sueño dentro de un sueño.

Calderón se divide en 16 capítulos o escenas, y tres interludios. Los interludios, constituyen el nivel de la realidad distanciada aún más de la acción de la trama. En ellos, el orador se dirige al público, discutiendo asuntos de naturaleza estética que conciernen la misma producción teatral. La obra, "un documento burgués" como lo define Van Watson (1983), reflexiona conscientemente sobre sí misma de manera crítica, y se revela aún más brechtiana al nivel siguiente, donde, aunque también esté distanciada del drama de acción, se comenta sobre esa acción escénica. En estas escenas, el rey Basilio y la reina Lupe hablan directamente al público, no como personajes, sino como portavoz del autor, y no se involucran en cuestiones estéticas, sino que tratan del significado político y de la belleza que se pueden obtener de la trama. El siguiente nivel es el nivel más tradicional de la acción dramática. La obra comienza con Rosaura que se despierta en un mundo que no reconoce. Se encuentra en una acomodada familia de clase media en Madrid. Encuentra a Segismundo que había sido amante de la madre antes de que ella se casara. Rosaura se enamora de Segismundo antes de descubrir que es su verdadero padre biológico. Más tarde se despierta para descubrirse prostituta en un barrio pobre en las afueras de Barcelona. Un chaval, Pablo es empujado por sus amigos a entrar en su choza, y en lugar de consumir una relación sexual con la prostituta, comienza a cortejarla con discursos filosóficos y revolucionarios. Rosaura se enamora de él, sólo para descubrir que es su hijo, que ella creía muerto --y que en cambio había sido vendido por su madre y su hermana. Cuando se despierta la tercera vez, el mundo y la vida real se convierten para ella muy real: ya no se llama Rosaura, sino María Rosa, y es una madre de una familia de clase media, casada con Basilio. Aquí niega su papel aún más categóricamente que antes, 
por lo que debe ser reportada a la orden en un hospital psiquiátrico. Tan pronto como se recupera, vuelve a casa. Fuera de casa tienen lugar tumultos estudiantiles, y uno de los estudiantes involucrados se introduce en la casa para refugiarse de la policía. Basilio empieza una diatriba en la que María Rosa y Pablo se duermen. Cuando se despierta, por cuarta vez, Rosaura se recuerda su vida sueño: vive en un lager, donde irrumpen los obreros con las banderas rojas. Basilio comenta que en ese momento empieza la vera tragedia:

Perché di tutti i sogni che hai fatto o che farai

si può dire che potrebbero essere anche realtà.

Ma, quanto a questo degli operai, non c'è dubbio:

esso è un sogno, niente altro che un sogno

(Pasolini, 2001: 758).

El final se queda abierto, como en suspensión, para enfatizar el nexo indisociable entre realidad y sueño, y no sólo por la relación especular entre los dos, sino por la situación común de los que hacen teatro. Ya que el teatro es real e irreal o surreal, sino también sueño.

\section{LOS DIVERSOS GRADOS DE METATEATRALIDAD}

El lector / espectador se introduce en Calderón de Pasolini especialmente por la estructura metateatral, y por la oscilación del sentido siempre suspendido entre realidad y ficción que es el tema básico de la pièce. Pero en esta obra desde el principio coexisten también otros elementos que juegan con la especularidad realidad / ficción.

Incluso sin tener que recurrir al artificio del teatro en el teatro -o de la representación incorporada en el marco de Las Meninas de Velázquez que retrae a la representación en su toma, de la que mencionaré algo más adelante--, limitándonos a los dos planos del drama, el externo y el interno a la representación, la misma convención del a parte a gli spettatori aquí interpretada por la figura del locutor (o como se llama en la obra de Pasolini, speaker), se basa, en última instancia, en un cambio momentáneo de nivel definido por Genette (1972: 243-46), metalepsis, es decir, la transición de un nivel a intra drammatico al nivel extra drammatico. Entre los diversos recursos dramatúrgicos, la transgresión de los cambios de nivel (de cualquier forma, espacial, temporal, o temática, ya que en esta obra los saltos de lugar, de tiempo y de tema son el fundamento de su construcción), confiere autenticidad, legitimidad y normalidad a la misma puesta en escena. En esta categoría cabe cualquier intrusión del actor (extra drammatico) en el mundo dramático o viceversa (caso a parte de los espectadores) o del personaje teatral en el universo metateatral, o viceversa. Y también del espectador involucrado en el drama, cuyo marco es circuncéntrico, según los niveles. 
En cuanto a la trama: ¿Es verdad o ficción la versión que da Rosaura de su sueño, en cada despertar?Y es sueño lo que Rosaura cuenta en sus tres despertares a su interlocutor de turno que se presenta como su hermana (Stella en el primero; Carmen en el segundo; Agostina, en el tercer despertar)? ¿O más bien es sueño lo que Rosaura está viviendo mientras le cuenta la realidad a su hermana? ¿Es ficción interpretada o realidad el estado de alucinación de Rosaura en el tercer despertar y también en el primero, en el hospital psiquiátrico?

Todos estos deslizamientos, transgresiones y rebotes de los niveles narrativos (el cuento del sueño de Rosaura, la revelación de que Rosaura es la hija de Segismundo confesado por él mismo, el cuento de la historia de éste y de la trama de La vida es sueño de Calderón; la revelación de que Rosaura es madre de Pablo, (hecha por el sacerdote que cuenta el hecho como una historia); y temáticos (por la diversidad y la variedad de las historias con respeto a la principal o central del despertar de Rosaura en un ambiente que no reconoce como suyo), implica una serie de referencias, de aplazamientos, de fugas y transgresiones de los niveles narrativos y también espacial y temporal (las historias que cuentan ocurrieron en otros lugares y en otras ocasiones) que enfatizan la metateatralidad del drama.

Por no mencionar los niveles de metateatralidad general que consiste en considerar las escenas que tienen lugar en el teatro desde el punto de vista nuestro como espectadores (por lo que la metateatralidad sería de tercer grado), o desde el punto de vista del interlocutor de Rosaura como personaje presenciando al desarrollo de lo que cree una representación, y el posterior relato del sueño, (en cuyo caso la metateatralidad es de segundo grado), o desde el punto de vista de los personajes que interpretan las historias que cuentan, como Rosaura cuando recuerda las demás vidas del sueño, o los recuerdos relatados por Segismundo: y se trata de piezas dialogadas en modo muy teatral (en este caso sería un metateatralidad de primero grado).

Aún no he asistido o visionado una puesta en escena de Calderón de Pasolini, y me he limitado en analizar sólo el texto para esta relación, pero supongo que, con base a la elección artística del director de la obra representada en teatro, la historia de los acontecimientos de estos personajes - que a nivel intradrammatico no lo son - estaría "interpretada" a los ojos de sus interlocutores en modo abiertamente y brechtianamente teatral, (también para respetar el sentido de ritualidad buscada por Pasolini, como se afirma en su Manifiesto para un nuevo teatro) incluso hablando directamente a la audiencia, "real", como si se tratara de un público imaginario, es decir, un público extradiegético de tercer grado.

Obviamente todas estas contorsiones metalépticas crean en el espectador una confusión de niveles, y por lo tanto una confusión sobre lo que es realidad y lo que es ficción; lo cual, obviamente, atrae al lector / espectador aún más activamente que un espectáculo tradicional. 


\section{REFERENCIAS BIBLIOGRÁFICAS}

ASOR ROSA, A. (2013). “Letteratura e storia, storia e letteratura: qualche modesta esperienza personale". En P. Favilli, (ed.). Il letterato e lo storico: la letteratura creativa come storia, 11-14. Milano: Franco Angeli.

ANNOVI, G. M. (2011). In the Theater of my Mind:Authorship, Personae, and the Making of Pier Paolo Pasolini's Work. Columbia University: ProQuest Dissertations Publishing.

BARILLI, R. (1970). “La metamorfosi della narrativa”. Introd. Robert Scholes y Robert Kellog, XI. La natura della narrativa. Bologna: II Mulino.

BARTHES, R. (1991). Lección inaugural de la cátedra de semiología lingüística del Còllege de France, 7 de enero de 1977. Madrid: Siglo XXI, 127-128.

BENEDETTI, C. (1998). Pasolini contro Calvino: per una letteratura impura. Torino: Bollati Boringhieri.

CASI, S. (2005). I teatri di Pasolini. Milano: Ubu libri.

DE FILIPPO, E. (1965). L'arte della commedia. Torino: Einaudi.

FAVILLI, P. (ed.) (2013). Il letterato e lo storico: la letteratura creativa come storia. Milano: Franco Angeli.

FORTINI, F. (1993). Attraverso Pasolini. Torino: Einaudi.

GENETTE, G. (1972). Discours du récit. Essai de méthode. Figures III. París: Seuil. 65-282 (Trad. esp. Barcelona: Lumen, 1989).

MUKARAMI, H. (2011). Entrevista en La Repubblica, 5 de noviembre.

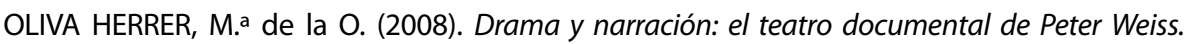
Valladolid: Universidad de Valladolid.

PASOLINI, P. P. (2001a). Calderón. En Teatro, Walter Siti \& Silvia De Laude (eds.). Milano: I Meridiani Mondadori.

(2001b). Per il cinema. Walter Siti \& Franco Zabagli (eds.), 2 vols. Milano: Mondadori. (2009). Passione e ideologia. Milano: Garzanti.

POZZI, G. (1981). La parola dipinta. Milano: Adelphi.

SANGUINETI, E. (1995). “Radicalismo e patologia”. Micromega 4, 213-220.

SITI, W. (2003). "L'opera rimasta sola”. Tutte le poesie 2, 1897-1946. Milano: Mondadori.

STAROBINSKJ, J. (1975). L'occhio vivente. Studisu Corneille, Racine, Stendhal, Freud. Torino: Einaudi. WATSON, W. V. (1987). Pier Paolo Pasolini and the theatre of the Word. ProQuest Dissertations and Theses. 
